The article "Exploring a cross-institutional research collaboration and innovation: Deploying social software and Web 2.0 technologies to investigate online learning designs and interactions in two Australian Universities" (Rossi et al., 2012) appeared in the Journal of Learning Design Volume 5, Issue 2 in 2012. Three years on, the authors reflect upon their original article.

\title{
Reflections on online learning designs and cross-institutional research collaborations: Revisiting "classrooms without walls" in two Australian universities
}

\section{Dolene Rossi}

School of Nursing and Midwifery CQUniversity

Australia

d.rossi@cqu.edu.au

Henriette van Rensburg

School of Linguistics, Adult and Specialist

Education

University of Southern Queensland

Australia

henriette.vanrensburg@usq.edu.au

Damien Clark

Office of Learning and Teaching

CQUniversity

Australia

d.clark@cqu.edu.au

\author{
R. E. (Bobby) Harreveld
}

School of Education and the Arts

CQUniversity

Australia

b.harreveld@cqu.edu.au

Colin Beer

Office of Learning and Teaching

CQUniversity

Australia

c.beer@cqu.edu.au

\author{
P. A. Danaher \\ School of Linguistics, Adult and Specialist Education \\ University of Southern Queensland, Australia \\ Adjunct Professor, School of Education and the Arts \\ CQUniversity \\ Australia \\ patrick.danaher@usq.edu.au
}

The article on which this paper reflects presented elements of a research project investigating learning interactions in online courses at two Australian universities. This paper revisits that earlier account of researching "classrooms without walls" by distilling and updating the authors' propositions and by examining these propositions' potential wider applicability. The twin foci of this examination relate to effective online learning designs and innovative cross-institutional research collaborations.

In celebration of the $10^{\text {th }}$ anniversary of the Journal of Learning Design's first issue, this contribution offers reflections on an earlier article in the journal (Rossi et al., 2012). That earlier publication presented selected elements of a cross-institutional research project that analysed specific types of learning interactions in five online courses at CQUniversity and the University of Southern Queensland, Australia (for a comprehensive overview, please see the project report (Rossi, van Rensburg, Beer, Clark, Danaher, \& Harreveld, 2013)). Three years after the publication of that article, it is timely to reconsider the article and the project to which it referred. Taking our cue from "What makes a good reflective paper?" (Walling, Shapiro, \& Ast, 2013), after a summary of the earlier article, we cluster our revisiting of the "classroom without walls" notion that framed the special theme issue in which the article appeared around two themes: 
- $\quad$ Effective online learning designs

- Innovative cross-institutional research collaborations.

The earlier article (Rossi, et al., 2012) offered a preliminary report in respect of a research project that utilised social software and Web 2.0 technologies to explore online learning designs and interactions across five courses offered by two Australian universities. The authors acknowledged that online learning environments constituted a contemporary characteristic within Australian universities. These educational contexts were described as "classrooms without walls" and the authors contended that the effectiveness of these learning environments were dependent upon the quality of the interactions that they fostered. The authors emphasised the importance of rigorous research to ensure that these learning innovations delivered enhanced and sustained learning outcomes. The researchers also analysed the utility of the social software and Web 2.0 technologies that had been deployed to facilitate their collaborative research. Attention was drawn to certain constraints and tensions attendant on within- and cross-organisational learning, teaching and research activities, and the article recorded evidence of innovation in the investigation of both online learning designs and the research project developed to evaluate the effectiveness and impact of those designs.

The issue of the requirements for effective online learning designs is even more significant than it was three years ago (Casey \& Wells, 2015). Educational institutions are increasingly seeking to balance pressures to accept more students into programs with the need to maximise the quality of the learning experiences and outcomes of those programs. This extremely complex balancing is demonstrated in contemporary research into theories of successful online learning, centered on learner-learner, learner-teacher and learner-content interactions, such as those analysed in Rossi's (2010) grounded theory study that became the pilot study for the research project reported here, and also in Beer's (2010) evaluation of appropriate measures of online student engagement, drawing on increasingly precise and useful learning analytics. Part of this complexity derives from the seeming ubiquity of learning management systems, which the authors likened to:

...the dirigibles of online education. Like the airships of a century ago, they are known for their skeletal rigidity, impermeable membranes filled with volatile gaseous variability of knowledge constructions, yet with gondola windows that enable passengers to connect to other worldly knowledges, while tethered to institutionalised entrance and egress points.

(Rossi, et al., 2013, p. 149)

This metaphor of the dirigible accentuates the diversity of the multiple manifestations of "classrooms without walls" and the obligation to enact strategies for supporting students that are contextually specific yet also based on principles of access and equity. The metaphor highlights also the fluidity of the technologies yet the rigidity of many of the systems attending the provision of online education. Clearly there is much still to be researched and understood in this domain.

With regard to such research, the article (Rossi, et al., 2012) on which this paper reports, traced some of the perils and possibilities of collaborative, including cross-institutional, research with which readers of this journal are familiar. The perils encompassed negotiating organisational approvals for the research in each university, the need for role clarity within the project team and increased work intensification for academics, among others. The possibilities traversed the significantly enhanced insights and understandings derived from the learning interactions among the members of an experienced, cross-disciplinary research team, as well as the empirical benefit of an expanded base for analysing courses across two universities.

Mobilising these perils and possibilities, and deploying anew the metaphor introduced in the preceding section of this paper, we affirm that "it is reasonable and even necessary to continue researching deep in the very fabric, frame and engine room of the dirigible as it ferries teachers and 
learners to and through university courses" (Rossi, et al., 2013, p. 149). In undertaking such research, it is important to build that partnership capital that can result from dynamic and vibrant collaborations, whose success is sometimes seen when partnerships outlive those who are immediately involved in them (Eddy, 2010). At the same time, it is crucial to acknowledge that partnerships - including research collaborations - generally entail the play of complex and sometimes contradictory benefits and interests (Cardini, 2006).

This timely opportunity to revisit our previous account of "classrooms without walls" in two Australian universities (Rossi, et al., 2012) has reaffirmed the increasing relevance of social software and Web 2.0 technologies underpinning online education. Doing so has also illustrated the accuracy of the dirigible as a metaphor for learning management systems in that education. Effective online learning designs and innovative cross-institutional research collaborations emerge as complex phenomena that we must strive to understand if they are to facilitate our work of enacting ethical and transformative education. 
The following presents the article as it appeared in 2012. With the authors' approval, minor edits have been made, the referencing updated to APA 6.0 and the numbering of figures altered to reflect the new publication.

\title{
Exploring a cross-institutional research collaboration and innovation: Deploying social software and Web 2.0 technologies to investigate online learning designs and interactions in two Australian universities
}

\author{
Dolene Rossi \\ School of Nursing and Midwifery \\ CQUniversity \\ Australia \\ R. E. (Bobby) Harreveld \\ School of Education \\ CQUniversity \\ Australia \\ Damien Clark \\ Office of Learning and Teaching \\ CQUniversity \\ Australia
}

\author{
Henriette van Rensburg \\ Faculty of Education \\ University of Southern Queensland, \\ Australia \\ Colin Beer \\ Office of Learning and Teaching \\ CQUniversity \\ Australia \\ P. A. Danaher \\ Faculty of Education \\ University of Southern Queensland, \\ Australia
}

\begin{abstract}
One significant manifestation of the proposition of a "classroom without walls" is the online learning environments evident in most contemporary Australian universities. A key element of the effectiveness of those environments is the quality of the interactions that they foster. Planning and implementing rigorous research into that quality is crucial if these particular "classrooms without walls" are to deliver enhanced and sustained learning outcomes. This article explores selected aspects of a cross-institutional collaboration linking two Australian universities researching the quality of learning interactions in their online courses. In particular, the authors analyse the utility of the social software and Web 2.0 technologies that have been deployed to facilitate their collaborative research. Despite the constraints and tensions attendant on withinand cross-organisational learning, teaching and research activities, the article records evidence of a developing innovation in investigating both the online learning designs and the research project developed to evaluate the effectiveness and impact of those designs.
\end{abstract}

\section{Keywords}

Cross-institutional collaboration, interactions, online learning design, research, social software, Web 2.0 technologies 


\section{Introduction}

Although partnerships are usually defined as necessary, pragmatic and benevolent ways of organizing social welfare, in practice they are complex, contradictory and even paradoxical social phenomena.

(Cardini, 2006, p. 394)

This article explores some of the principles and practices of learning design enacted in specific types of interactions evident in selected online courses helping to constitute the "classroom without walls" dimension of two Australian universities. The focus is on the use of social software and Web 2.0 technologies by a research project team comprised of staff members from both universities. The article outlines the possibilities of and the constraints on this particular crossinstitutional research collaboration (encapsulated in Cardini's [2006] statement above) and thereby analyses elements of innovation in both the learning design of the courses under review and the research project investigating the interactions occurring in those courses. The article consists of the following four sections:

- A selective literature review and conceptual framework

- The study's research design

- The study's data collection and analysis

- Concluding implications for maximising innovation in both the learning design of online courses and cross-institutional research projects.

\section{Literature review and conceptual framework}

Learning design in online environments is clearly as complex as it is diverse. Online educators are exhorted to promote social presence (Kehrwald, 2007; Lloyd, 2011), to facilitate spiral learning (Schuetze, 2010) and to enact transformative learning (Reushle \& Mitchell, 2009). These and other approaches to online learning design are directed at enhancing learner engagement and at maximising successful outcomes for learners and educators alike.

This complexity and diversity are key features of the possibilities for innovation and transformation afforded by online environments. These possibilities range from technologyfacilitated authentic learning designs (Oliver, Herrington, Herrington, \& Reeves, 2007) to writing non-linear learning resources (Turner, 2007) to using contemporary social software to underpin enduring collaborations among learners, educators and researchers (Duff, Spangenberg, Carter, \& Miller, 2010).

A crucial element of effective learning design in online environments is the promotion of meaningful and productive interactions (Saiki, 2010), despite the absence of definitional consensus about such interactions (Beuchot \& Bullen, 2005). Current scholarship has demonstrated that interactions are an important element of successful online learning ( $\mathrm{Su}$, Bonk, Magjuka, Lui, \& Lee, 2005), and that they are inextricably linked with knowledge construction (Rossi, 2010). Interaction types include learner-learner, learner-teacher, learner-content, teacher-teacher, teachercontent and content-content (Anderson, 2008), as well as learner-interface (Hillman, Willis, \& Gunawardena, 1994). There are also close connections between specific interaction types and the principles and practices of online learning design (Chou, 2002).

Understandably the scholarship examining online learning continues to grow (Cavanaugh, Barbour, \& Clark, 2009; Means, Toyama, Murphy, Bakia, \& Jones, 2009). Some of that 
scholarship has involved cross-institutional research collaborations (Arnold, Ducate, Lomicka, \& Lord, 2009), including research into inter-university online delivery projects (Bonk, Lee, Kim, \& Lin, 2009). Some of these research collaborations have been facilitated by the use of social software and Web 2.0 technologies, the latter having been defined "as a second generation, or more personalised, communicative form of the World Wide Web that emphasises active participation, connectivity, collaboration and sharing of knowledge and ideas among users" (McLoughlin \& Lee, 2007, p. 665).

Despite these technological affordances, and although cross-institutional research collaborations can yield productive dividends (Davies \& Salisbury, 2009), such collaborations are often complex and contested (Kurasawa, 2007). Collaboration has been theorised by D'Amour, Ferrada-Videla, San Martin Rodriguez and Beaulieu (2005) as the interplay of five key concepts: sharing, partnership, power, interdependency and process. Yet they acknowledged that we still have limited comprehension of complex professional relationships, and that much remains to be understood about the connections between the elements and the outputs of collaborations. More broadly, while the cross-institutional research project reported in this article was officially described as a partnership within an agreement endorsed and signed by representatives from both universities and the external funding body, such partnerships often conceal inter- and intra-organisational tensions and sometimes competing interests (Cardini, 2006). As Cardini noted, "external pressures, diversity of motives and purposes amongst partners as well as variations and curtailment of funds often lead to instability, conflict and premature dissolution" (p. 397).

\section{Research design}

Despite these conceptual and practical complexities, the members of this collaborative partnership have aspired to reach cross-institutional and multidisciplinary understandings of the patterns, processes and consequences of learner-content, learner-learner and learner-teacher interaction in postgraduate and undergraduate online courses. The study's research design draws from and builds on previous research conducted by members of the project team. One of these investigations utilised academic analytics to examine the adoption of learning management system (LMS) features and staff and student engagement within online courses (Beer, Jones, \& Clark, 2009). Results of this investigation suggested that the analysis of LMS data in conjunction with student results could be used to provide the institution with benchmark information and an indicator of student engagement within online courses. The second investigation examined the processes of, and the relationship between, learner-learner interaction and knowledge construction within an online communication course, which led to the articulation of a substantive theory about learning relationships in online contexts (Rossi, 2010). The current project has utilised a collective case study approach to respond to the following research questions:

- RQ 1: How do learners interact in online courses?

- RQ 2: What are the patterns, processes and consequences of learner-learner and learnerteacher interaction in online contexts?

Five online courses were purposefully selected as cases within the study. Case study facilitates the investigation of contemporary phenomena in real-life settings. It is also an effective means of uncovering contextual conditions through different forms of evidence (Baxter \& Jack, 2008; Yin, 2003). One or more phenomena may be selected as a unit of analysis when its characteristics are thought to have significant implications for the case being investigated (Patton, 2002). An embedded case design, such as the one employed in this study, offers the opportunity to emphasise different aspects of each course and provides multiple foci for the analysis of data which facilitates the identification of different levels at which statements about conclusions may be made (Yin, 
2003). Learner-learner interaction, learner-teacher interaction and learner-content interaction constituted discrete units of analysis within this cross-institutional study.

The course selected as a case within Rossi's (2010) investigation served as a pilot within the current investigation. The additional four cases included an online postgraduate and undergraduate level course offered by each educational institution. Figure 1 outlines the processes associated with a case study approach, demonstrates the relationship between these processes and the collaborative research project discussed within this article and illustrates the complexity of the phenomena being examined. The substantive theory and associated model constructed to illustrate the key aspects in the development of learning relationships in online contexts (Rossi, 2010) served as a tool through which to view data from the current study.

How do learners interact in online courses?

What are the patterns, processes and consequences of learner-learner and learnerteacher interaction in online contexts?

\begin{tabular}{|l|c|c|}
\hline $\begin{array}{l}\text { Anderson/Moore } \\
\text { Learner Interaction }\end{array}$ & $\begin{array}{c}\text { Socio-constructivist theories of } \\
\text { learning \& teaching }\end{array}$ & $\begin{array}{l}\text { Online interaction \& the } \\
\text { concept of presence }\end{array}$ \\
\hline
\end{tabular}
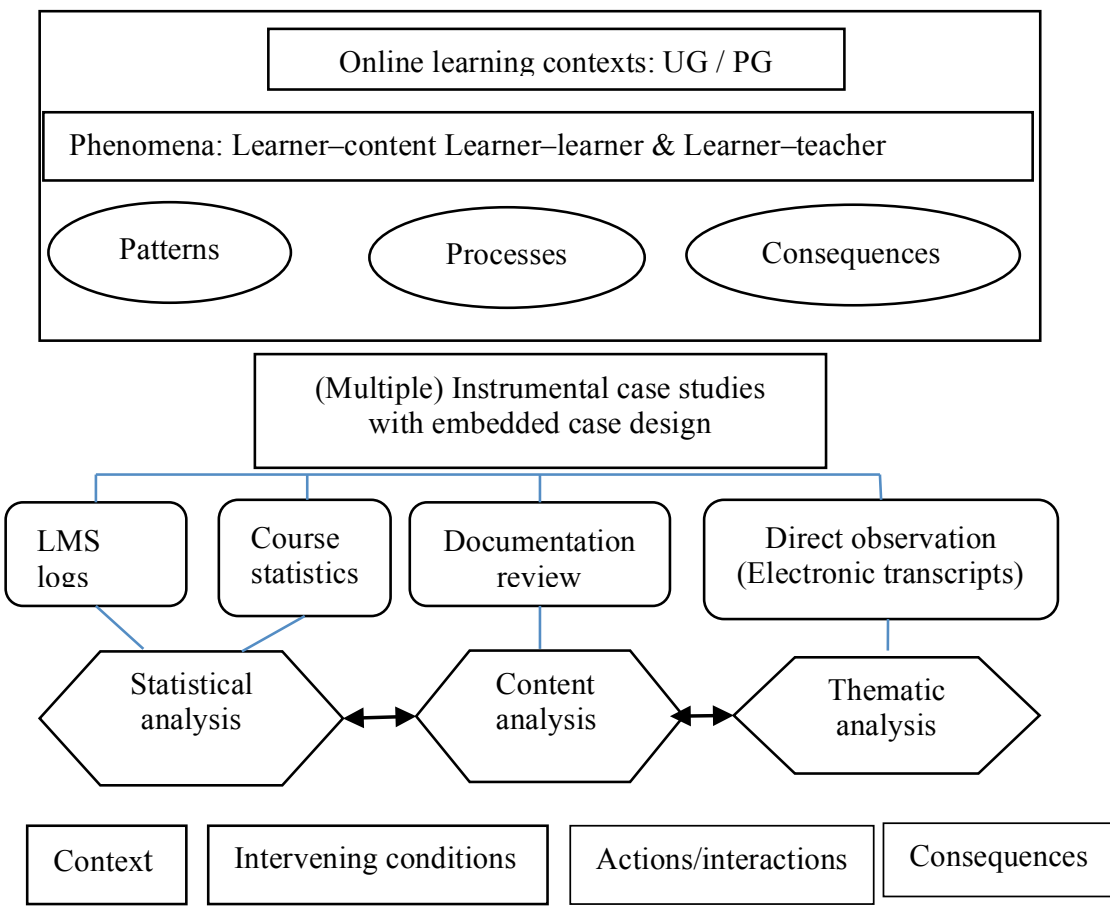

Data reduction and display

Descriptive matrices/Interpretive

\section{Comparative analysis}

Descriptive matrices/Interpretive

Drawing and verifying conclusions

Descriptive matrices/Interpretive
Pose the research question/s

Identify the underpinning theories

Determine the case/s its/their context/s and the phenomenon/a of interest

Determine the specific case study approach

Identify the data collection methods most suitable to answer the research questions

Select analysis strategies appropriate to each of these data collection strategies

Refine the data through the analytical filter

Use matrices to reduce data into manageable chunks and conceptual groupings

Comparative analyses of collective (multiple) cases

Determine conclusions and develop case descriptions

Figure 1. Case study schematic (adapted from Rosenberg \& Yates, 2007) 
Within the framework afforded by this research design, the component of the research project focusing on the cross-institutional collaborative dimension of the study was facilitated by the use of social software and Web 2.0 technologies to collect and analyse the data reported below. We see that use as contributing to the emergent innovation that we elaborate below as characterising the research collaboration as well as the online course design at the centre of that collaboration.

\section{Data collection and analysis}

Social software and Web 2.0 technologies were integrally involved in the collection and analysis of the data related to this parallel study of the online learning designs and interactions and of the cross-institutional research collaboration investigating those designs and interactions. For ease of presentation, we discuss these two elements of the study separately in this section of the article, then we distill common implications of these elements in the conclusion below.

\section{Online learning designs and interactions}

The principal sources of data within the study of the online learning designs and interactions were electronic transcripts, retrieved retrospectively from an archive of each of the five courses, and selected as a case. Additional data included information obtained from non-interactive, static records produced by the LMS in the form of system logs and course statistics, and program and course documentation. The LMS for the pilot course was Blackboard and for the other courses was Moodle, which is the LMS used at present by both universities. The analysis of these data is currently proceeding using NVivo software and framed by the research questions outlined above.

The proposition of a "classroom without walls" is commonly associated with e-learning, online education and virtual delivery of that education (Lai \& Ng, 2011; Raffaghelli \& Richieri, 2010). The aspirations attendant on this proposition were encapsulated in the statement that "The socalled 'classroom without walls' may soon become the classroom without boundaries that supports continuous learning on demand as we exchange skills for access, knowledge for acquisition, and experience for relationships" (Atkinson, 2009, p. 31). Certainly the analysis to date of the online learning designs and interactions confirm the existence of several distinctive affordances of educational technologies that make possible new forms of student engagement and learning. On the other hand, that analysis highlights the complexity of learning and teaching in online environments. It demonstrates also that any enactment of these distinctive affordances and possibilities is neither automatic nor easy, but instead occurs only as the result of working simultaneously across a range of fronts.

Indeed, without wishing to pre-empt the subsequent findings of the ongoing analysis of the five courses, there are emerging indications from that analysis of the confirmation - and in some areas potentially the elaboration - of the elements of a theory of online learning depicted in Figure 2. These elements were distilled in Rossi's (2010) grounded theory study of what became the pilot study in this investigation. At the same time, given that the project has broadened the focus to include learner-learner and learner-content as well as learner-learner interactions, it is likely that the analysis will yield outcomes that contribute to extending current understandings of the centrality of interactions in sustainable online learning and of the principles and practices of effective learning design necessary to facilitating that learning. 


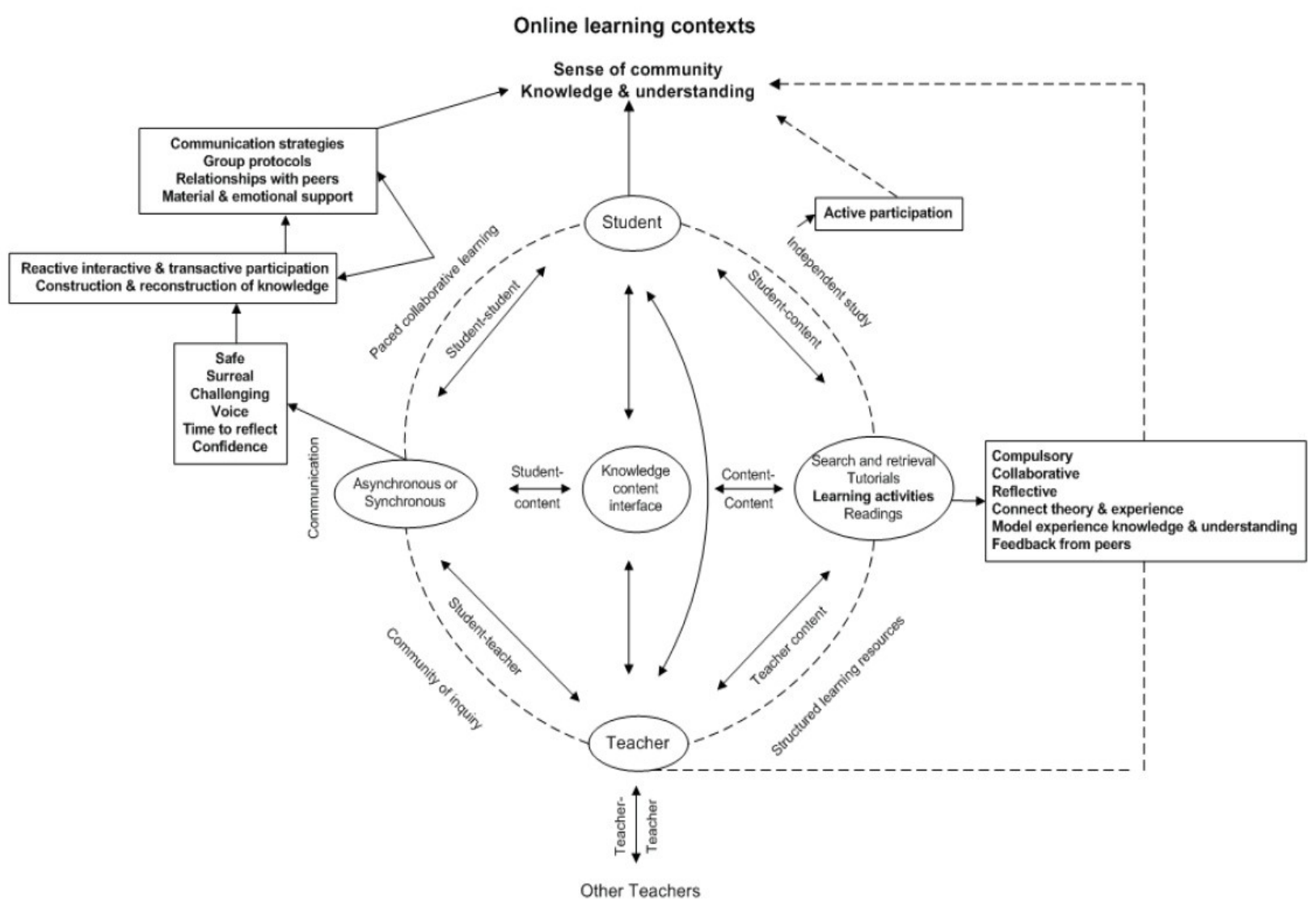

Figure 2. Elements of a theory of online learning (Rossi, 2010, p. 234)

\section{Cross-institutional research collaboration}

The cross-institutional research collaboration was pursued through a number of interaction types that provided the data analysed here about this component of the study. These interactions included a fortnightly videoconference, occasional teleconferences, regular and ongoing emails across the project team as a whole and among individual team members, a two-day face-to-face meeting at one of the universities (to be followed by an equivalent meeting at the other university in the final third segment of the funding period) and several efforts to use contemporary research collaboration software in order to create, manage, share and disseminate the team's developing knowledge base. These efforts drew on Google Docs ${ }^{1}$, Dropbox ${ }^{2}$, the data fabric technology of the eResearch Collaborative Services provided by the Australian Research Collaboration Service ${ }^{3}$ and a wiki that will be progressively developed to report the project's findings.

One crucial set of issues in this research collaboration was clustered around negotiating organisational approvals in each university. These approvals related to submitting the project proposal, agreeing to the version of the project approved by the external funding body, obtaining human ethics panel approval for subsequent analysis of student data at the end of each selected course and one university assigning to the other access to student data from two of those courses so that the other university could apply its academic analytics software to those courses. While all these approvals have been gained, each took more time and involved more discussion and documentation than we had anticipated at the outset of the project.

\footnotetext{
${ }^{1}$ http://www.google.com/google-d- s/b1.html

$2 \mathrm{http}: / /$ www.dropbox.com

${ }^{3} \mathrm{http}: / /$ www.arcs.org.au
} 
More broadly, the complexity of obtaining these approvals highlights key features of contemporary universities and of the work and identities of those who work in them. These features include ongoing competition for scarce resources, heightened managerialism, work intensification, blurred role boundaries and reduced autonomy (see also Bexley, James, \& Arkoudis, 2011). These administrative and cultural challenges in implementing effective crossinstitutional research collaborations are offset by the development and enhancement of dynamic professional relationships that often extend beyond individuals moving from one university to another and that provide a vital foundation for the bureaucratic dimension of the collaborations. Indeed, these relationships have often ensured the continuation of the project when it might have foundered at times when making progress in dislodging seemingly insurmountable obstacles has appeared difficult and stressful. (Importantly, the same points can be made in relation to collaboration across different sections within the same university - for example, schools, faculties and divisions, research centres, the research office including human ethics and research funding, technical support and the legal office.)

This same interplay between obstacles to collaboration and professional relationships that have found solutions to those obstacles has been evident in the project team's efforts to use social software and Web 2.0 technologies to create, manage, share and disseminate our knowledge of the project and our developing research findings. We continue to experiment with means of communicating among ourselves and with multiple others in ways that use the affordances of particular technologies as effectively and efficiently as possible. For example, this article was developed using email attachments; future publications are likely to use collaborative software such as Google Docs. We have found that the take up of specific technologies has been influenced by diverse technical knowledge and technological experience within the team, varied understandings of research and publishing, and different ways of working that have emerged over time and that are sometimes resistant to change. Perhaps inevitably these efforts at enhancing our cross-institutional research collaboration have entailed continuing trial and error and have highlighted the need for time to practise using specific technologies before these technologies are incorporated into our separate and shared research practices.

\section{Conclusion}

This article has identified several constraints on the extent to which social software and Web 2.0 technologies have been successfully incorporated into the online learning designs and interactions and into the cross-institutional research project currently exploring those designs and interactions. These constraints have clustered around individuals' and groups' capacities and preparedness to engage wholeheartedly and dialogically with the technologies and with the other participants in the courses and the project. Wider issues such as organisational context and direction and sector-wide shifts in teaching, learning and research priorities have influenced those capacities.

Despite these constraints, there is developing evidence of indicators of innovation in both the online learning designs and interactions and the cross-institutional research collaboration outlined above. For example, course-specific strategies have been demonstrated as being successful in promoting sustainable learner-learner, learner-teacher and learner-context interactions in different ways across the five courses analysed to date in the project. Similarly, there are instances of highly effective learning design in selected aspects of the courses, including in matching course goals and assessment tasks and in using the activity logs afforded by the LMS as a trigger for monitoring student engagement and for ongoing course evaluation. Likewise the writing of the technical scripts for the academic analytics (Beer, Jones, \& Clark, 2009) and the grounded theory study (Rossi, 2010) leading to the pilot study in this project constitute significant contributions to extending existing theoretical, methodological and practice-based knowledge that augur well for the current analysis of the main study. 
In combination, these constraints on and indicators of innovation suggest a number of implications for enhancing the prospects for innovation in learning design and research collaboration alike. First, recalling that innovation is as much about the transformation of practice as it is about the creation of new ideas (Denning, 2004) is a timely reminder that practice is often deeply engrained over time and can take equivalent time to change and transform. Second, innovation depends as much on the trust and goodwill of participants as it does on externally circulated possibilities for change and transformation. Third, the social and cultural dimensions of technologies are as significant as their technical features in influencing their take up in particular contexts for specific purposes. Fourth, conducting teaching, learning and researching in online environments affords distinctive possibilities but also creates certain complexities that can prevent those possibilities from being realised.

All of this suggests that online learning designs and interactions, and cross-institutional research collaborations to investigate those designs and interactions, can certainly create new ways of working cross-culturally and inter-organisationally. Furthermore, they can generate effective and sustainable innovations that can arise from new ideas and that can transform taken-for-granted practice. Moreover, social software and Web 2.0 technologies can play crucial roles in supporting and disseminating these new ways of working and innovations. At the same time, all these possibilities are constrained by the limitations of collaborations and partnerships (Cardini, 2006; D’Amour, Ferrada-Videla, San Martin Rodriguez, \& Beaulieu, 2005) noted above. We look forward to elaborating the interplay between these possibilities and constraints as the research project continues to unfold.

\section{References}

Anderson, T. (2008). Towards a theory of online learning. In T. Anderson (Ed.), The theory and practice of online learning ( 2 ed., pp. 1-14). Edmonton, AB: Athabasca University Press.

Arnold, N., Ducate, L., Lomicka, L., \& Lord, G. (2009, Summer). Assessing online collaboration among language teachers: A cross-institutional case study. Journal of Interactive Online Learning, 8(2), 121-139.

Atkinson, T. (2009, May/June). Second Life TM for educators: Teaching and learning. TechTrends, $53(3), 30-32$.

Baxter, P., \& Jack, S. (2008, December). Qualitative case study methodology: Study design and implementation for novice researchers. The Qualitative Report, 13(4), 544-559.

Beer, C., Jones, D., \& Clark, K. (2009, December 6-9). The indicators project identifying effective learning: Adoption, activity, grades and external factors. Paper presented at the 26 annual conference of the Australasian Society for Computers in Learning in Tertiary Education, University of Auckland, Auckland, New Zealand.

Beer, C. (2010). Online student engagement: New measures for new methods. Unpublished Masters dissertation, CQUniversity, Rockhampton, Qld, Australia.

Beuchot, A., \& Bullen, M. (2005). Interaction and interpersonality in online discussion forums. Distance Education, 26(1), 67-87.

Bexley, E., James, R., \& Arkoudis, S. (2011, September). The Australian academic profession in transition: Addressing the challenge of reconceptualising academic work and regenerating the academic workforce (Commissioned report prepared for the Department of Education, Employment and Workplace Relations). Melbourne, Australia: Centre for the Study of Higher Education, University of Melbourne. 
Cardini, A. (2006). An analysis of the rhetoric and practice of educational partnerships in the UK: An arena of complexities, tensions and power. Journal of Education Policy, 21(4), 393-415. doi: 10.1080/02680930600731773

Casey, G., \& Wells, M. (2015). Remixing to design learning: social media and peer-to-peer interaction. Journal of Learning Design, 8(1), 38-54. doi:10.5204/jld.v8i1.225

Cavanaugh, C. S., Barbour, M. K., \& Clark, T. (2009, February). Research and practice in K-12 online learning: A review of open access literature. International Review of Research in Open and Distance Learning, 10(1). Retrieved from http://www.irrodl.org/index.php/irrodl/article/view/607/1183

D’Amour, D., Ferrada-Videla, M., San Martin Rodriguez, L., \& Beaulieu, M.-D. (2005, May). The conceptual basis for interprofessional collaboration: Core concepts and theoretical frameworks. Journal of Interprofessional Care, Supplement 1, 116-131.

Davies, S. M. B., \& Salisbury, J. (2009, July). Building educational research capacity through inter-institutional collaboration: An evaluation of the first year of the Welsh Education Research Network (WERN). Welsh Journal of Education, 14(2), 78-94.

Denning, P. (2004, April 21-27). Building a culture of innovation. Ubiquity, 5(8), 1-13.

Duff, A., Spangenberg, B., Carter, S., \& Miller, J. (2010). The gang's all here: Grammar goes global for Purdue, UNISA and Adelaide University. Journal of Learning Design, 4(1), 32-40. doi:10.5204/jld.v4i1.67

Eddy, P. (2010). Special issue: Partnerships and collaborations in higher education. ASHE Higher Education Report, 36(2), 1-115. doi: 10.1002/aehe.3602

Hillman, D. C. A., Willis, D. J., \& Gunawardena, C. N. (1994). Learner-interface interaction in distance education: An extension of contemporary models and strategies for practitioners. American Journal of Distance Education, 8(2), 30-42.

Kehrwald, B. A. (2007). Social presence and learner support: Understanding learners' experiences with mediated social processes in text-based online learning environments. Unpublished Doctor of Philosophy dissertation, Faculty of Education, University of Southern Queensland, Toowoomba, Qld, Australia.

Kurasawa, F. (2007, Fall). The state of intellectual play: A generational manifesto for neoliberal times. Topia: Canadian Journal of Cultural Studies, 18. Retrieved from http://pi.library.yorku.ca/ojs/index.php/topia/article/view/13249

Lai, Y. C., \& Ng, E. M. W. (2011, January). Using wikis to develop student teachers' learning, teaching, and assessment capabilities. The Internet and Higher Education, 14(1), 15-26.

Lloyd, M. (2011). A tale of six fish: Achieving social presence through discussion forums in an offline learning environment. Journal of Learning Design, 4(2), 39-51. doi:10.5204/jld.v4i2.74

Means, B., Toyama, Y., Murphy, R., Bakia, M., \& Jones, K. (2009, May). Evaluation of evidencebased practices in online learning: A meta-analysis and review of online learning studies. Washington, DC: Office of Planning, Evaluation, and Policy Development, United States Department of Education. Retrieved from http://repository.alt.ac.uk/629/1/US_DepEdu_Final_report_2009.pdf

Oliver, R., Herrington, A., Herrington, J., \& Reeves, T. (2007). Representing authentic learning designs supporting the development of online communities of learners. Journal of Learning Design, 2(2), 1-21. doi:10.5204/j1d.v2i2.36

Patton, M. Q. (2002). Qualitative research and evaluation methods $\left(3^{\mathrm{rd}}\right.$ ed.). Thousand Oaks, CA: Sage. 
Raffaghelli, J. E., \& Richieri, C. (2010). A classroom with a view: Net-based strategies to promote intercultural education. In L. Dirckinck-Holmfeld, V. Hodgson, C. Jones, M. de Laat, D. McConnell, \& T. Ryberg (Eds.), Proceedings of the $7^{\text {th }}$ International Conference on Networked Learning (pp. 327-335). Retrieved from http://www.lancs.ac.uk/fss/organisations/netlc/past/nlc2010/abstracts/PDFs/Raffaghelli.pdf

Reushle, S., \& Mitchell, M. (2012). Sharing the journey of facilitator and learner: Online pedagogy in practice. Journal of Learning Design, 3(1), 11-20. doi:10.5204/jld.v3i1.45

Rosenberg, J. P., \& Yates, P. (2007). Schematic representation of case study research designs. Journal of Advanced Nursing, 60(4), 447-452.

Rossi, D. M. (2010, January). Learning relationships in online contexts: A substantive theory constructed from the integrated analyses of learner-learner interaction and knowledge construction in an undergraduate communication course. Unpublished Doctor of Philosophy dissertation, Faculty of Education, University of Southern Queensland, Toowoomba, Qld, Australia.

Rossi, D., van Rensburg, H., Harreveld, R., Beer, C., Clark, D., \& Danaher, P. (2012). Exploring a cross-institutional research collaboration and innovation: Deploying social software and Web 2.0 technologies to investigate online learning designs and interactions in two Australian Universities. Journal of Learning Design, 5(2), 1-11. doi:10.5204/jld.v5i2.108

Rossi, D. M., van Rensburg, H., Beer, C., Clark, D., Danaher, P. A., \& Harreveld, R. E. (2013). Learning interactions: A cross-institutional multi-disciplinary analysis of learner-learner and learner-teacher and learner-content interactions in online learning contexts (DeHub report series 2013). Armidale, Australia: DeHub, University of New England. Retrieved from http://acquire.cqu.edu.au:8080/vital/access/services/Download/cqu:10119/ATTACHMENT01?ope $\mathrm{n}=$ true

Saiki, D. (2010). Interacting online: A content analysis of museum education websites. Journal of Learning Design, 4(1), 52-62. doi:10.5204/jld.v4i1.69

Schuetze, U. (2010). Spiral learning: An introductory course on reading LOTE online. Journal of Learning Design, 4(1), 24-31. doi:10.5204/jld.v4i1.66

Su, B., Bonk, C. J., Magjuka, R. J., Lui, X., \& Lee, S. (2005). The importance of interaction in web-based education: A program-level case study of online MBA courses. Journal of Interactive Online Learning, 4(1). Retrieved from http://www.ncolr.org/jiol/issues/PDF/4.1.1.pdf

Turner, M. (2007). Contemporary approach to writing non-linear online learning resources. Journal of Learning Design, 2(2), 70-82. doi:10.5204/j1d.v2i2.42

Walling, A., Shapiro, J., \& Ast, T. (2013, January). What makes a good reflective paper? Family Medicine, 45(1), 7-12.

Yin, R. K. (2003). Case study research: Design and methods ( ${ }^{\text {rd }}$ ed.). Thousand Oaks, CA: Sage. 


\section{Acknowledgments}

This paper and the earlier article relate to a project funded in 2011-2012 by the DeHub Consortium, hosted by the University of New England, Australia. Administrative support was provided by Ms Tash Toon, Ms Chriss Lenz and Ms Mary Cranston at the Learning and Teaching Education Research Centre at CQUniversity, Australia. The project evaluator was Professor Michael Singh in the Centre for Educational Research at the University of Western Sydney, Australia. The project reference group was chaired by Professor Terry Evans (formerly at the School of Education, Deakin University, Australia) and included Professor Nita Temmerman (formerly at the Faculty of Education, University of Southern Queensland, Australia), Dr Abdurrahman Umar (formerly at the Commonwealth of Learning, Canada) and Professor Steve McKillup and Ms Beth Tennent (currently and formerly at CQUniversity, Australia). In relation to the earlier article, the authors thank the guest editors of the special theme issue of the journal in which it appeared and acknowledge the feedback of two anonymous peer reviewers. The authors are also grateful to Professor Margaret Lloyd for the invitation to reprint the article and to write this accompanying reflection.

Copyright (c) 2015 Dolene Rossi, Henriette van Rensburg, R. E. (Bobby) Harreveld, Colin Beer, Damien Clark and Patrick Danaher 